1 Diving behaviour of Atlantic salmon at sea - effects of light regimes and

2

\title{
temperature stratification
}

3

4

Running head: Diving behaviour of Atlantic salmon at sea

5

6 Richard D. Hedger* 1,2, Audun H. Rikardsen², Jon F. Strøm², David A. Righton³, 7 Eva B. Thorstad ${ }^{1,2}$, Tor F. Næsje ${ }^{1}$

8

$9 \quad{ }^{1}$ Norwegian Institute for Nature Research (NINA), N-7485 Trondheim, Norway

$10 \quad{ }^{2}$ Department of Arctic and Marine Biology, University of Tromsø, N-9037 Tromsø, Norway

$11{ }^{3}$ Centre for Environment, Fisheries and Aquaculture Science, NR33 0HT Lowestoft, UK

*Corresponding author: richard.hedger@nina.no

13 
14

15

ABSTRACT: The diving behaviour of adult Atlantic salmon (Salmo salar L.) post-spawners in the Norwegian and Barents Seas was monitored with pop-up satellite archival tags (PSATs) and data storage tags (DSTs). Atlantic salmon from the three populations studied showed similar depth use patterns. Tagged specimens spent most of their time near the surface (mean of $82 \%$ of the time at depths $<10 \mathrm{~m}$ ), with occasional short deep dives ( $>200 \mathrm{~m}$ depth, median time $=2.31 \mathrm{~h}$, range $=0.18-22.5 \mathrm{~h}$ ), the deepest recorded being $707 \mathrm{~m}$. Increased use of greater depths occurred during daytime than night-time in the months between polar day and polar night (August-October). Diurnal behaviour around the time of polar night (NovemberJanuary) was weakest for the population (from the River Alta) that migrated furthest north. Diving was more frequent and shallower when the mixed layer was near to the surface during the months of June-October. There was an increase in diving depth ( $>200 \mathrm{~m})$ when the mixed layer extended to 200-300 m in winter and spring (December-April). Deep diving consisted of ' $U$ ' shaped dives, possibly indicative of foraging. We hypothesise that seasonal light conditions, dependent on geographical location, affect Atlantic salmon diving, and that changes in diving depth may be due to seasonal differences in prey aggregation.

Key-words Continental shelf, deep sea, feeding, fish, migration, Arctic, North East Atlantic 
Atlantic salmon (Salmo salar L) are anadromous and undertake oceanic feeding migrations during post-smolt (early adult) and adult post-spawning life-stages (see Dadswell et al. 2010, Miller et al. 2014). They are opportunistic feeders at sea, with their main prey being fish larvae, small epipelagic and mesopelagic fishes, planktonic and large crustaceans, and squid (Hansen \& Quinn 1998, Jacobsen \& Hansen 2000, Rikardsen \& Dempson 2011). In the North Atlantic, Atlantic salmon prey such as herring (Clupea harengus L.), sand eels (Ammodytes spp.) and amphipods have defined distributions, influenced by the North Atlantic current (Haugland et al. 2006). Thus, the geographic and depth distribution of Atlantic salmon within the North Atlantic may partly reflect that of their prey (Dadswell et al. 2010). excess of $100 \mathrm{~m}$ have been observed using telemetry for both post-smolt and post-spawned Atlantic salmon, however, this behaviour appears to be related to the stage of migration and the geographical area (Holm et al. 2006, Lacroix 2013, Godfrey et al. 2015, Gudjonsson et al. 2015). Diving may also be related to foraging and predator avoidance (Reddin et al. 2011). Reddin et al. (2004) proposed a model for energy optimisation by Atlantic salmon involving diving to cold water layers for foraging, and returning to warmer surface waters for digestion. Such thermal regulation has been observed for Pacific Salmon (Oncorhynchus spp.) in temperate marine areas, with Chum Salmon (Oncorhynchus keta) observed diving into cooler layers, presumably to minimise energy use (Tanaka et al. 2000). However, there would seem to be little advantage to this behaviour in colder northern waters. 
In this study, we examined the diving behaviour and activities of adult Atlantic salmon postspawners in the Norwegian and Barents Seas using individuals from three populations originating from Norwegian Rivers, the Orkla, Alta and Neiden, tagged with either pop-up satellite archival tags (PSATs) or data storage tags (DSTs). We compared long-term (monthly) and short-term (hourly) changes in depth use by individuals from the three populations to examine the influence of light regimes on depth use. We also examined diving for 13 individuals from the Alta population tagged with high resolution DSTs of 1 or 5 minute intervals to examine the influence of light and thermal regimes on diving behaviour.

(6)

Fish telemetry: pop-up satellite archival tags and data storage tags

Adult Atlantic salmon were sampled and tagged in three Norwegian rivers: the Orkla River $\left(63.3^{\circ} \mathrm{N}, 9.7^{\circ} \mathrm{E}\right)$, the Alta River $\left(70.0^{\circ} \mathrm{N}, 23.4^{\circ} \mathrm{E}\right)$, and the Neiden River $\left(69.7^{\circ} \mathrm{N}, 29.4^{\circ} \mathrm{E}\right)$

(Figure 1a). The Orkla and Alta Rivers discharge into the Norwegian Sea through

Trondheimsfjord and Altafjord respectively, and the Neiden River discharges into the Barents

Sea through Neidenfjord. The Norwegian and Barents Seas are categorised as subarctic/Arctic seas, with sea surface temperatures ranging between $\approx 15^{\circ} \mathrm{C}$ in summer and $\approx 0^{\circ} \mathrm{C}$ in winter, and thermally stratified waters from July to September/October. Atlantic salmon were caught in the rivers by angling in late April - early May for the Orkla River and mainly from May 10-22 for the Alta and Neiden Rivers (no difference between years in terms of capture time) during their seaward migration period (see Halttunen et al. 2010). Mainly females were retained for tagging as these generally have a higher survival in both the river and sea (Halttunen et al. 2013), but some males were also tagged ( $\approx 7 \%$ of all tagged individuals). The 
Atlantic salmon were kept in storage pens to allow acclimation to sea, before they were anaesthetised for surgery (2-phenoxy-ethanol, $0.5 \mathrm{ml} \mathrm{l}^{-1}$, mean anaesthetising time $=3 \mathrm{~min}$ ). Each Atlantic salmon individual was cradled in a $25 \mathrm{~cm}$ diameter water-filled tube for tagging. The top half of this tube had been removed to enable surgery, but the part surrounding the head of the individual undergoing surgery was kept intact to ensure that light intensity at the individual's eyes was minimised. Water ensured that the head and gills were submerged. Individuals from the Orkla and the Alta rivers were tagged with either a PSAT or a DST, whereas all individuals from the Neiden River were tagged with PSATs (Table 1). All individuals were released between May 3 and June 1 .

PSATs (Microwave Telemetry, Inc.) had a mass of $40 \mathrm{~g}$ and were $120 \mathrm{~mm}$ in length, $32 \mathrm{~mm}$ in diameter and had a $185 \mathrm{~mm}$ antenna. A PSAT was attached externally to each Atlantic salmon individual by bridling the tag to two cushioned back-plates. Back-plates were wired through the dorsal musculature below the dorsal fin with two biocompatible plastic-coated stainless steel wires. The inside of these plates had been surfaced with biocompatible silicon pads to reduce skin abrasion. A multifilament nylon thread attached each plate to the PSAT so that the PSAT streamed $\approx 1-2 \mathrm{~cm}$ behind the dorsal fin. PSATs were programmed to pop-up: at a specified date (in most cases after 156 days at sea), or if the PSAT crossed a maximum depth threshold (1200 m) to prevent tag destruction from high water pressure, or registered a constant depth. Although PSATs recorded depth and temperature data at short intervals $(\approx 1-2$ minutes), bandwidth limitations of data transmission to satellite after pop-up allowed only a 15 minute, or coarser, temporal resolution. PSATs had their position of pop-up registered by the ARGOS satellite positioning system. The limited battery life of PSATs precluded their use for long-term (>1 year) study. 
109 DSTs (Star-Oddi Ltd) were $39 \mathrm{~mm}$ long and $13 \mathrm{~mm}$ in diameter, and had a mass of $9.2 \mathrm{~g}$.

110 DSTs measured depth and temperature at a constant interval (1-30 minute depending on the

111 tag) over a long-term period ( $>1$ year). Each DST was inserted to the peritoneal cavity

112 according to the method described in Rikardsen and Thorstad (2006). Recaptures in the DST

113 program were dependent on fishers. An information sheet was sent to fishers in the fjords and

114 attached rivers before the commencement of the fishing season each year explaining how to

115 return the tag, with a reward of 1200 NOK ( $\approx 140$ USD) for successful return.

117 PSAT time-series were examined to identify if tagged Atlantic salmon had died due to

118 predation or another reason. Adult Atlantic salmon at sea are eaten by whales (Cetacea spp.),

119 seals (Phocidae spp.), sharks (Selachimorpha spp.), Atlantic bluefin tuna (Thunnus thynnus),

120 skates (Rajidae spp.) and Atlantic halibut (Hippoglossus hippoglossus) (Joyce et al. 2002,

121 Rikardsen et al. 2008, Lacroix 2014). As these species have depth use and diving patterns that

122 differ from Atlantic salmon, predation could be identified from an abrupt change in depth and

123 diving pattern from that of Atlantic salmon. Temperatures indicative of the tag passing

124 through the alimentary canal of an endothermic predator also indicated predation. A

125 continuous reading of the tag at the sea bottom was taken to indicate that the Atlantic salmon

126 individual was dead. PSAT data recorded after the identification of such a death point were

127 removed from further analysis.

128

129 To avoid the data sampling interval causing bias in our analyses of behaviour, tag data were

130 divided into two categories: low ( $\geq 10 \mathrm{~min}$ ) and high resolution (1 or $5 \mathrm{~min}$ ). Both low and

131 high resolution data were used for comparison of depth use patterns among the populations

132 (Orkla, Alta and Neiden). High resolution data available for 13 Alta Atlantic salmon tagged

133 with DSTs were used in a more detailed analysis of their diving behaviour. Low resolution 
134 data were not used to analyse diving behaviour because of the potential to not record short

135 dives. Diving behaviour was examined only for individuals tagged with small internally

136 implanted DSTs to reduce the potential for introducing behavioural bias in diving behaviour

137 which may be associated with large external PSATs (see Hedger et al. 2017).

138

\section{Comparison of populations (Orkla, Alta and Neiden)}

140

141 To evaluate if there were differences in maximum diving depth according to where the

142 Atlantic salmon from the three populations had migrated, the maximum depth recorded

143 leading up to pop-up (from the day of and day preceding pop-up) of the PSATs was compared

144 with the water column depth at the site of pop-up. Water column depth at the site of pop-up

145 was determined by cross-referencing the location of the tag (determined by ARGOS satellite

146 positioning) with the water column depth of that location, obtained from GEBCO - General

147 Bathymetric Chart of the Ocean. Based on a maximum swimming distance of $\approx 50 \mathrm{~km} \mathrm{~d}^{-1}$ (see

148 Lacroix 2013), the maximum fish depth recorded on the day of and day preceding pop-up will

149 have occurred within $100 \mathrm{~km}$ of the position measured using the ARGOS system.

150

151 The depth distributions of the three populations were examined for temporal trends. Firstly,

152 the depth frequency distribution, median, and maximum depth of Atlantic salmon from the

153 three populations were examined for monthly changes. Hourly depth frequency distributions

154 of the populations were examined seasonally for May - July (approximating polar day),

155 August - October (the months between polar day and polar night), and November - January

156 (approximating polar night)

157 
160 Mean absolute vertical velocity (vertical distance moved between tag depth registrations over

161

162

tag registration interval) was calculated as a function of hour of day for three times of the year: May - June (polar day for the latitude of the Alta River), August - October (the months between polar day and polar night), and November - January (polar night).

Dives below the euphotic zone ( $>200 \mathrm{~m}$ depth) were examined with regard to diving and surfacing velocities, maximum diving depth, time length of dive and change in temperature experienced. All dives (>25 m) and deep dives (> $200 \mathrm{~m}$ ) were examined on a monthly basis to determine if there were long-term trends in relation to stratification, which could be indicative of a change in the availability of food. Stratification of the water column was defined as the depth of the mixed layer, as determined from the operational TOPAZ4 Arctic Ocean system (data provided by the Copernicus Marine Environment Monitoring Service). The relationship between the depth of all dives (>25 m) and the depth of the mixed layer was determined using a Generalised Estimation Equation (GEE) model (R function geeglm(geepack library)), with clustering of data according to individual.

Atlantic salmon migrated away from the coast to deep waters, as shown by the location of pop-up of PSATs (Figure 1). Of all PSATs for which data could be recovered ( $n=66$ out of 73 fish released, 90\%), 47 (71\%) popped-up due to constant pressure, 15 (23\%) on the pre-set pop-up date, three were recaptured, and one measured a depth exceeding maximum threshold. Pop-ups resulting from a registration of a constant depth or a depth greater than the maximum 
183 threshold occurred in 50\% of the Orkla PSATs releases, $67 \%$ of the Alta PSAT releases and

$184100 \%$ of the Neiden PSAT releases. Pop-ups occurred from the end of May, several weeks

185 after release, until April the following year: no seasonal differences for time of pop-up were 186 apparent for the Orkla or Neiden populations; however, the Alta population showed greatest

187 numbers of pop-ups in November and December. Recovery rates for DSTs, indicative of a 188 return from the sea and recapture, were 5.2\% and 6.1\% for Orkla and Alta Atlantic salmon 189 respectively.

190

191 Recovered data for both individuals tagged with PSATs and individuals tagged with DSTs

192 showed that the Atlantic salmon were pelagic, with occasional short forays into the water

193 column. Atlantic salmon spent a mean of $81.6 \%$ of the time at depths $<10 \mathrm{~m}$ (SD $=11.8 \%$,

$194 \min =20.8 \%, \max =99.9 \%, \mathrm{n}=104 \mathrm{fish}$ ) and a mean of $87.8 \%$ of the time at depths $<25 \mathrm{~m}$

$195(\mathrm{SD}=10.4 \%, \min =20.8 \%, \max =100 \%, \mathrm{n}=104$ fish $)$. Atlantic salmon spent the vast

196 majority of time within the euphotic zone ( $<200 \mathrm{~m}$ depth) $($ mean $=98.6 \%$ of the time, $\mathrm{SD}=$

$1971.41 \%, \min =94.4 \%, \max =100 \%, \mathrm{n}=104$ fish). Thirteen individuals (out of 104) did not

198 dive deeper than $100 \mathrm{~m}$ and 26 did not dive deeper than $200 \mathrm{~m}$. The greatest depth recorded

199 for individuals from the Orkla River was $610.6 \mathrm{~m}(\mathrm{SD}=221.3$, $\min =17.5, \mathrm{n}=13$ fish), 706.7

$200 \mathrm{~m}(\mathrm{SD}=178.3, \min =14.1, \mathrm{n}=77 \mathrm{fish})$ for the Alta River and $347.0 \mathrm{~m}(\mathrm{SD}=113.1, \mathrm{~min}=$

$20121.5, \mathrm{n}=14$ fish) for the Neiden River.

202

203

Comparison of populations (Orkla, Alta and Neiden)

204

205 The Atlantic salmon from the different populations migrated to different areas (Figure 1),

206 which appeared to influence the likelihood of deep dives. Pop-ups from the Orkla population

207 mainly occurred in the western Norwegian Sea around the Mid-Atlantic ridge between 
208 Iceland and Svalbard. Pop-ups from the Alta population occurred in two regions: (i) along the 209 Mid-Atlantic ridge, nearer to Svalbard than Iceland and (ii) in the Barents Sea. Pop-ups from the Neiden population occurred in the Barents Sea, with the exception of two individuals that

211 migrated northward to Svalbard. Near the time of pop-up (day of and day preceding pop-up),

212 dive depths depended on geographical location. Individuals within the Barents Sea (east of

$21315^{\circ} \mathrm{E}$ ) dived to significantly greater depths (median $=120 \mathrm{~m}, \min =0 \mathrm{~m}, \max =519 \mathrm{~m}, \mathrm{n}=$

21431 ) than those in deeper waters, offshore in the Norwegian Sea (west of $\left.15^{\circ} \mathrm{E}\right)($ median $=2 \mathrm{~m}$,

$215 \min =0 \mathrm{~m}, \max =196 \mathrm{~m}, \mathrm{n}=20)($ Wilcoxon rank sum test, $\mathrm{W}=211, \mathrm{p}=0.028)$.

217 Long-term (monthly) and short-term (diurnal) trends in depth use were evident in all three 218 populations. Atlantic salmon from the Alta and the Orkla spent more time at depths $>5 \mathrm{~m}$ 219 during the summer months of July to October, less during the autumn/winter months of 220 November to February, and then more again during the spring months of March to May 221 (Figure 2, upper panels). Individuals from the Neiden population only provided data until 222 January following release, but showed a similar pattern of greater occupancy of depths $>5 \mathrm{~m}$ 223 during summer than winter. Median depths were mostly within the upper $10 \mathrm{~m}$ of the water 224 column, but a seasonal trend was present, with shallower median depths immediately after sea entry (May) and during winter (December-February) than in summer, followed by a return to deeper median depths (for the Alta and the Orkla individuals) in the following spring (Figure

227 2, middle panels). Dive depth increased as the Atlantic salmon migrated away from their 228 release points, and Orkla and Alta individuals typically dived to 100-200 m from March the 229 year after release (Figure 2, lower panels).

231 Diurnal patterns in depth use depended on time of year (Figure 3). In the first few months 232 after release (May - July, where there was polar day at high latitudes), there was no diurnal 
233 trend in depth use. However diurnal trends were evident later (August - October, where there 234 was a mixed daytime/night-time regime), with greater depths being registered from 6:00 235 18:00 Hrs than from 18:00 - 1600 Hrs (as measured by the clock, calibrated to the position of 236 release). Even later (November - January, where there was polar night at high latitudes), this 237 diurnal behaviour was apparent, but the period of use of greater depths was confined to a 238 shorter number of hours during the day. Diurnal behaviour from November to January was 239 weakest for individuals from the River Alta.

Vertical movements were greater during day than night (Figure 4), however, the tendency to diurnal patterns was strongly dependent upon time of year. During times approximating the polar day and polar night for the latitudes of the River Alta and northwards, there was a much weaker diurnal pattern than during the season between polar day and night. When Atlantic salmon experienced a 24 hour day-night cycle, mean vertical velocities ranged from $\approx 0.5 \mathrm{~m}$ $\min ^{-1}$ at $24: 00$ Hrs to $\approx 1.65 \mathrm{~m} \mathrm{~min}^{-1}$ at $12: 00 \mathrm{Hrs}$ (from the tag clock calibrated to position of release).

Visual inspection showed that most deep dives ( $>200 \mathrm{~m})$ followed a ' $U$ ' shape $(\approx 42.1 \%$ of deep dives) rather than a ' $\mathrm{V}$ ' shape pattern, with an initial rapid descent, followed by a period of time lingering at depth and concluding with a rapid ascent to the surface (Figure 5a). Diving velocities were $\approx 0.5 \mathrm{~m} \mathrm{~s}^{-1}$ near to the dive's initiation and declined to $0 \mathrm{~m} \mathrm{~s}^{-1}$ over a period of $\approx 20$-30 minutes as the trough of the dive was approached. There was typically little vertical movement at depth until the individual accelerated towards the surface to finish the dive. Some dives showed a skewed ' $U$ ' shape in which there was a slight surfacing trend 
258 before the individual rapidly swam towards the surface ( $\approx 22.2 \%$ of deep dives) (Figure $5 \mathrm{~b})$. A 259 smaller number of dives showed a ' $U$ ' shape in which the individual dived with an initial 260 rapid descent, before a slow approach of the trough of the dive ( $\approx 7.6 \%$ of total dives $)$. Other

261 dives showed more complex patterns. Firstly, some dives were generally 'U’ shaped but

262 involved multiple short-term vertical movements around the trough of the dive $(\approx 22.0 \%$ of

263 total dives) (Figure 5c). Other dives involved occupancy of a distinct sill depth, where the

264 individual remained for an extended time before or after the individual dived to deeper depths $265 \quad(\approx 6.2 \%$ of total dives) (Figure $5 \mathrm{~d})$.

267 Overall, the descending phase was significantly faster than the ascending phase (Wilcoxon 268 signed rank test, $\mathrm{V}=91, \mathrm{p}<0.001, \mathrm{n}=13$ fish) (Figure 6a). The mean of individual descent 269 velocities was $0.20 \mathrm{~m} \mathrm{~s}^{-1}$ (range $=0.11-0.35 \mathrm{~m} \mathrm{~s}^{-1}, \mathrm{n}=13$ fish), and on ascent $0.10 \mathrm{~m} \mathrm{~s}^{-1}$ 270 (range $=0.05-0.18 \mathrm{~m} \mathrm{~s}^{-1}, \mathrm{n}=13$ fish). The proportion of deep dives was inversely 271 proportional to the dive depth, with only $1.8 \%$ of dives to $>600 \mathrm{~m}$ depth (Figure $6 \mathrm{~b}$ ). Deep

272 diving events lasted for several hours (median time $=2.31 \mathrm{~h}$, range $=0.18-22.5 \mathrm{~h}, \mathrm{SD}=2.03$

273 h) (Figure 6c). Diving typically involved relatively small decreases in temperature (median = $\left.274 \quad 0.4^{\circ} \mathrm{C}, \max =5.8^{\circ} \mathrm{C}\right)($ Figure $6 \mathrm{~d})$.

276 Deep diving events were aperiodic and the time between successive deep dives was highly 277 positively skewed, with more than $20 \%$ of surfacing events from a deep dive followed by a 278 subsequent deep dive less than 15 mins later. However, a similar percentage of surfacing 279 events involved the individual staying at the surface for more than two days, and one 280 individual went for 74 days between deep dives. Some individuals occasionally spent long periods on the surface without performing deep dives, followed by multiple successive deep 
282

dives. Atlantic salmon exhibited both shallow and deep dives throughout the year, but the overall diving pattern was associated with changes in the mixed layer depth (Figure 7a). When the mixed layer was near to the surface (depth $<50 \mathrm{~m}$, June - October), most dives were relatively shallow. When the depth of the mixed later increased (depth $150-250 \mathrm{~m}$, mid-November - May), dives tended to be deeper. Diving depth (Figure 7b) increased with the depth of mixed layer (GEE, $p<0.001$, cluster $n=13$ ). The diving rate showed a similar seasonal pattern. The rate of all dives $>25 \mathrm{~m}$ was strongly related to time of year, with diving rate being greatest in summer (peaking in August and September), and lowest during winter (reaching a minimum in December) (Figure 7c). In contrast, the rate of deep dives (>200 m) was greater during winter (when the mixed layer depth had deepened) than during summer.

\section{DISCUSSION}

This study has used two different tag types - PSATs and DSTs - to elucidate diving behaviour in tagged Atlantic salmon individuals from three populations. The use of the different tag types was not consistent among the populations, with $\approx 71 \%$ (Orkla), $\approx 55 \%$ (Alta) and 100\% (Neiden) of individuals being tagged with PSATs rather than DSTs. Given this, it is necessary to consider the potential for tag effects to bias results of the study. Hedger et al. (2017) showed that although depth distributions among Atlantic salmon individuals tagged with PSATs were broadly similar to those of individuals tagged with DSTs, those tagged with PSATs tended to dive to shallower depths and dived less frequently than those tagged with DSTs. This may have slightly biased our estimates of overall depth distributions when comparing populations. However, the consistency in seasonal trends in depth behaviour among populations in the current study suggests that a mix of tags may still be applied effectively to compare populations. For analysis of environmental influences on diving 
307 behaviour, the current study focused on the high resolution DSTs, so differential tag effects 308 were not an issue.

312 Atlantic salmon from the three populations showed similar depth use and diving patterns

313 during their marine migration. Firstly, all populations showed a trend of increasing use of

314 subsurface waters (depth $>5 \mathrm{~m}$ ) from release until later summer (August), followed by a return

315 to greater occupancy of surface waters in winter (December - February). Secondly, all

316 populations showed similar changes in diurnal patterns, with no diurnal variation during May

317 - July, and increased use of greater depths during daytime in August - October. During

318 November - January, Orkla and Alta populations showed little diurnal pattern, whereas there

319 was more use of greater depths for $\approx 4$ hours around 12:00 Hrs (using the tag clock calibrated 320 to position of release) for the Orkla population.

322 Although the Atlantic salmon came from three different populations, they were migrating to 323 waters similar in terms of surface temperature and depth of the mixed layer, so it is not that 324 surprising that they showed similarities. In comparison, stocks of North American Atlantic 325 salmon have shown different diving patterns (Reddin et al. 2011, Lacroix 2013, Strøm et al. 326 2017) which may be related to differences in environmental conditions between the current 327 study and those conducted in North American locations. 
Atlantic salmon behaviour in the initial phase of sea migration was not dominated by deep dives. There was little diving in the first month after release despite the fact that fjord and coastal zone depths could exceed several hundred metres. This is consistent with results from previous studies of Atlantic salmon kelts and post-smolts, both in the North West Atlantic and the North East Atlantic, showing swimming through the near surface layers with a lack of deep diving (LaBar et al. 1978, Davidsen et al. 2008, Halttunen et al. 2009, Gudjonsson et al. 2015). Diet studies of Atlantic salmon in the fjords of this study show that Atlantic salmon post-smolts feed almost exclusively on fish (Rikardsen et al. 2004). Post-smolts of other salmonids - Arctic charr (Salvelinus alpinus L.) and sea trout (Salmo trutta L.) - in the Altafjord have been found to feed pelagically on herring (Rikardsen \& Amundsen 2005) when the prey was abundant. Given that adult Atlantic salmon in the current study were in poor condition on first entering the sea (median condition factor $(K)=0.74)$, it can be expected that they would have had the impetus to feed. Thus we propose that they were feeding pelagically in the first month at sea during the transit away from the coast when prey were available.

Further from release, some individuals did show occasional dives (depths of $200-400 \mathrm{~m}$ ) in summer (June - August) (Supplementary figure 1). This is suggestive of them having moved off the continental shelf into the Norwegian Sea. Lacroix (2013) observed deep dives when post-spawners crossed the deep Laurentian Channel or migrated to the edge of the continental shelf, and hypothesised that they may have been looking for a thermal refuge or orientation cues, or feeding in highly productive upwelling water at the continental shelf edge. Given that deep dives at this time were rare occasional events, we hypothesise that this is an example of exploratory and orienteering behaviour rather than foraging behaviour, triggered by the Atlantic salmon moving from coastal to deeper waters. 
356

In the winter and spring following release, the Atlantic salmon behaviour changed to deep

diving. Greater maximum depths were observed for all populations in winter, and for the

358

Orkla and Alta individuals tagged with DSTs that had extended coverage into the spring. In addition, the frequency of deep diving increased for the Alta Atlantic salmon tagged with high-resolution DSTs. Atlantic salmon in the deep sea have been shown to feed on the mesopelagic community, both in the NW Atlantic (Lear 1972) and the NE Atlantic (Hansen \& Pethon 1985). This may be the cause of the deep dives shown in the current study. Near the time of pop-up, Atlantic salmon which had migrated to the deeper part of the Norwegian Sea (from the Orkla and one-third of the Alta population) dived within the water, but to shallower depths than those that migrated to the shallow Barents Sea (from the Neiden and two-thirds of those from the Alta population). Differences in diving depths may indicate different feeding behaviours. Prey fish for adult Atlantic salmon, including herring, capelin (Mallotus villosus), and sand eel (Haugland et al. 2006, Rikardsen \& Dempson 2011, Renkawitz et al. 2015), are found throughout the Norwegian and Barents seas (see Jakobsen \& Ozhigi 2011), but there is limited information on how their distributions change spatially and temporally, so it is difficult to relate the diving behaviours of Atlantic salmon in these seas to differences in prey availability. Some of the deep dives within the Barents Sea preceding pop-up were deep enough that they may have been diving to the sea bottom, so the Atlantic salmon could also have been feeding on benthic related prey items. However, the ability for Atlantic salmon to quickly migrate allowed for the possibility that they could have been diving in deeper waters before a pop-up took place at a relatively shallow location.

\section{Environmental influences on diving}


380

381

382

383

384

385

386

387

388

389

390

391

392

393

394

395

396

397

398

399

400

401

402

403

404

Short- and long-term changes in the depth frequency distribution of all populations, and in the vertical velocities of the Alta Atlantic salmon tagged with high resolution DSTs, are likely associated with changes in light. Adult Atlantic salmon at sea have been shown to dive more during daytime than night-time and/or occupy nearer surface waters at night-time (Holm et al. 2006, Reddin et al. 2011, Renkawitz et al. 2012, Lacroix 2013). Atlantic salmon from all rivers in the current study showed a diurnal pattern of depth occupancy, that was attenuated during polar day and polar night. Depth did not change according to hour of day from May to July, during the polar day. Thus, the lack of diurnal changes in depth use during this period may be related to the small diurnal variation in light intensity. Later in the year (August October), periods of night-time began to return, which was associated with increased use of greater depths during daylight. Later in the winter (November - January), PSAT data suggest that Atlantic salmon from all three populations were in northern latitudes. During this time, both the length of daylight and twilight were short, which were associated with shorter periods ( $\approx 4$ hours) of use of greater depths for the Orkla and Neiden Atlantic salmon. When the daytime lasted a short period, the greatest depth use of Neiden Atlantic salmon occurred 4 hours earlier than noon at the local time of the River Neiden (for which the tag clock was set). Therefore, if they were diving during the brightest conditions around noon during the short winter day it is likely that Neiden Atlantic salmon had moved $\approx 60^{\circ}$ east of the release site. Of the three populations, the Alta Atlantic salmon had the least difference in depth according to time of day during winter. This suggests that the Alta Atlantic salmon were at latitudes with smaller daily differences in light intensity i.e., were farther north. The Alta Atlantic salmon tagged with high resolution DSTs showed a similar pattern. Vertical movements for the Alta Atlantic salmon were greatest in August - October when there was greatest diurnal contrast in illumination. These vertical movements would be consistent with visual foraging during the daytime period. 
406 Diurnal variation in depth use by Atlantic salmon may be directly affected by variation in 407 light conditions by creating opportunities for visual foraging. Indirect effects of light are also possible if they feed on prey that have diurnal vertical migrations. Atlantic salmon are able to

409 feed in the dark, as evident from them feeding in darkness under ice cover (Finstad et al.

410 2004). However, foraging would likely be more efficient if they can use their visual sense.

411 Therefore, the depth at which Atlantic salmon feed may be a function of prey location and 412 relative visual feeding efficiency. If most prey were deeper in the water column, occupancy of 413 greater depths would be expected during brighter periods of the day (see Reddin et al. 2011),

414 when Atlantic salmon can use their vision to forage which would concur with the 415 seasonal/diurnal depth patterns observed in this study.

Diving behaviour was probably not related to suboptimal summer or winter thermal conditions. Reddin (2011) proposed that during stratification in summer Atlantic salmon dived for short periods of time to catch prey despite cold suboptimal conditions and return to 420 the surface to digest prey. Lacroix (2013) hypothesised that adult Atlantic salmon avoided the 421 surface layer in the Labrador Sea during winter because supercooling caused surface temperatures to fall below a critical threshold of $-0.76{ }^{\circ} \mathrm{C}$ (see Saunders 1986 , Fletcher et al. 1988). However, neither of these conditions were observed in our study. It was rare for a

424 Atlantic salmon to dive into temperatures below the critical threshold, and the temperature 425 change during dives was not great, with $\approx 87 \%$ of dives never involving a reduction in 426 temperature of $>2^{\circ} \mathrm{C}$. Median surface (depth $<5 \mathrm{~m}$ ) temperatures during winter (December 427 January) were 3.6, 4.3 and $5.2^{\circ} \mathrm{C}$ for Orkla, Alta and Neiden populations, respectively, so 428 Atlantic salmon were not experiencing supercooling near the surface. This was because 429 variation between winter and summer in terms of sea surface temperature is less for the North 
430 East Atlantic, where this study was based, than that for the North West Atlantic. Thus the 431 difference between Atlantic salmon behaviour in this study and that of Reddin (2011) and 432 Lacroix (2013) may be due to the different environments. It is also unlikely that diving 433 behaviour was influenced by low oxygen levels in the mesopelagic. Hypoxia in Atlantic 434 salmon occurs at dissolved oxygen (DO) levels below $6 \mathrm{mg} \mathrm{l}^{-1}$ (Burt et al. 2013). Predictions 435 by the TOPAZ4 Arctic Ocean Biogeochemistry Analysis and Forecast always showed DO 436 levels greater than $8 \mathrm{mg} \mathrm{l}^{-1}$ throughout the mesopelagic in the Norwegian and Barents Sea, so 437 Atlantic salmon in the current study were not diving into conditions likely to induce hypoxia.

439 Changes in the frequency and diving depth of Alta Atlantic salmon tagged with high

440 resolution DSTs coincided with changes in stratification, with frequent shallow dives during near-surface stratification, and a reduction in the rate of shallow dives but an increase in the rate of deep dives when the mixed layer extended to a depth of several hundred metres.

443 Diving has been related to stratification in other marine fishes. Waller et al. (2009), for example, found that Atlantic bluefin tuna showed preference for surface layers when in 445 strongly stratified waters, spent less time above the thermocline when in weakly stratified 446 waters, and dived to depths that were positively related to the depth of the thermocline. They speculated that strong thermal stratification may facilitate prey detection and improve the chance of successful feeding. Atlantic salmon in the current study dived to deep waters only 449 after a relatively long period at sea. The delay may be related to the deepening of the mixed 450 layer, and consequent changes in prey aggregation. Deep (>200 m) diving exhibited by Alta 451 Atlantic salmon with high-resolution DSTs was characterised by relatively infrequent and 452 short duration ' $U$ '-shaped dives. These 'U' shaped dives have been hypothesised to be 453 indicative of foraging behaviour in bluefin tuna (Wilson \& Block 2010), and this may be the 454 case for the adult Atlantic salmon in the current study. 


\section{CONCLUSION}

457

458 Diurnal and seasonal patterns in depth use and diving were broadly consistent among groups

459 of tagged Atlantic salmon in the northern part of the North East Atlantic. This was manifested 460 as use of greater depths during daylight on a daily time scale. Seasonally, this involved use of 461 deeper depths in summer, more use of nearer-surface depths at the onset of winter, and a 462 return to more use of deeper depths in late winter and spring with a concurrent increase in 463 deep dives (>200 m) into the water column. The diurnal effect was likely associated with 464 changes in light-regime, as suggested by transitions in behaviour between polar day and polar 465 night. The seasonal pattern of deep diving may have been influenced by seasonal trends in the 466 depth of the mixed layer, which we hypothesise affects diving behaviour by aggregating 467 sources of prey.

468

\section{ACKNOWLEDGEMENTS}

470

471 We thank the Tromsø Research Foundation (supported by Trond Mohn), the Norwegian

472 Research Council (project 221400/E40), Alta Laksefiskeri Interessentskap and the University

473 of Tromsø for financial support to the Salmotrack-project during the period 2008-2017. 


\section{REFERENCES}

475

476

477

478

480

481

482

483

484

485

486

487

488

489

490

491

492

493

494

495

496
Burt K, Hamoutene D, Perez-Casanova J, Gamperl AK, Volkoff H (2013) The effect of intermittent hypoxia on growth, appetite and some aspects of the immune response of Atlantic salmon (Salmo salar). Aquaculture Research 45:124-137

Dadswell MJ, Spares AD, Reader JM, Stokesbury MJW (2010) The North Atlantic subpolar gyre and the marine migration of Atlantic salmon Salmo salar: the 'Merry-Go-Round' hypothesis. J Fish Biol 77:435-467

Davidsen JG, Manel-la NP, Okland F, Diserud OH, Thorstad EB, Finstad B, Sivertsgard R, McKinley RS, Rikardsen AH (2008) Changes in swimming depths of Atlantic salmon Salmo salar post-smolts relative to light intensity. J Fish Biol 73:1065-1074

Finstad AG, Forseth T, Næsje TF, Ugedal O (2004) The importance of ice cover for energy turnover in juvenile Atlantic salmon. J Anim Ecol 73:959-966

Fletcher GL, Kao MH, Dempson JB (1988) Lethal freezing temperatures of arctic char and other salmonids in the presence of ice. Aquaculture 71:369-378

Godfrey J, Stewart D, Middlemas S, Armstrong J (2015) Depth use and migratory behaviour of homing Atlantic salmon (Salmo salar) in Scottish coastal waters. ICES J Mar Sci

Gudjonsson S, Einarsson SM, Jonsson IR, Gudbrandsson J (2015) Marine feeding areas and vertical movements of Atlantic salmon (Salmo salar) as inferred from recoveries of data storage tags. Can J Fish Aquat Sci 72:1087-1098

Halttunen E, Jensen JLA, Naesje TF, Davidsen JG, Thorstad EB, Chittenden CM, Hamel S, Primicerio R, Rikardsen AH (2013) State-dependent migratory timing of postspawned Atlantic salmon (Salmo salar). Can J Fish Aquat Sci 70:1063-1071 
Halttunen E, Rikardsen A, Davidsen J, Thorstad E, Dempson J (2009) Survival, migration speed and swimming depth of Atlantic salmon kelts during sea entry and fjord migration. Tagging and Tracking of Marine Animals with Electronic Devices, Book 9, 9037. Springer Netherlands

Halttunen E, Rikardsen AH, Thorstad EB, Naesje TF, Jensen JLA, Aas O (2010) Impact of catch-andrelease practices on behavior and mortality of Atlantic salmon (Salmo salar L.) kelts. Fish Res 105:141-147

Hansen L, Quinn T (1998) The marine phase of the Atlantic salmon (Salmo salar) life cycle, with comparisons to Pacific salmon. Can J Fish Aquat Sci 55(Suppl. 1)

Hansen LP, Pethon P (1985) The food of Atlantic salmon, Salmo salar L., caught by long-line in northern Norwegian waters. J Fish Biol 26:553-562

Haugland M, Holst JC, Holm M, Hansen LP (2006) Feeding of Atlantic salmon (Salmo salar L.) postsmolts in the Northeast Atlantic. ICES J Mar Sci 63:1488-1500

Hedger RD, Rikardsen AH, Thorstad EB (2017) Pop-up satellite archival tag effects on the diving behaviour, growth and survival of adult Atlantic salmon Salmo salar at sea. J Fish Biol 90:294310

Holm M, Jacobsen J, Sturlaugsson J, Holst J (2006) Behaviour of Atlantic salmon (Salmo salar L.) recorded by data storage tags in the NE Atlantic - implications for interception by pelagic trawls. ICES ASC

Jacobsen JA, Hansen LP (2000) Feeding Habits of Atlantic Salmon at Different Life Stages at Sea. In: Mills D (ed) The Ocean Life of Atlantic Salmon: Environmental and Biological Factors Influencing Survival. Wiley-Blackwell, Oxford 
518 Jakobsen T, Ozhigi V (2011) The Barents Sea: Ecosystem, Resources, Management - Half a Century of Russian-Norwegian Cooperation. Tapir Academic Press, Trondheim

520 Jákupsstovu SHí (1988) Exploitation and migration of salmon in Faroese waters. Atlantic Salmon: Planning for the future. Croom Helm, London

Joyce WN, Campana SE, Natanson LJ, Kohler NE, Pratt HL, Jensen CF (2002) Analysis of stomach contents of the porbeagle shark (Lamna nasus Bonnaterre) in the northwest Atlantic. ICES J Mar Sci 59:1263-1269

LaBar GW, McCleave JD, Fried SM (1978) Seaward migration of hatchery-reared Atlantic salmon (Salmo salar) smolts in the Penobscot River estuary, Maine: open water movements. Journal du Conseil international pour l' Exploration de la Mer 38:257-269

Lacroix GL (2013) Population-specific ranges of oceanic migration for adult Atlantic salmon (Salmo salar) documented using pop-up satellite archival tags. Can J Fish Aquat Sci 70:1011-1030

Lacroix GL (2014) Large pelagic predators could jeopardize the recovery of endangered Atlantic salmon. Can J Fish Aquat Sci 71:343-350

Lear WH (1972) Food and feeding of Atlantic salmon in coastal areas and over oceanic depths. Research Bulletin International Commission for the Northwest Atlantic Fisheries 9:27-39

Miller AS, Miller TJ, Mills KE, Sheehan TF (2014) Retrospective analysis of Atlantic salmon (Salmo salar) marine growth and condition in the northwest Atlantic based on tag-recovery data. Fisheries Oceanography 23:103-115 Atlantic salmon (Salmo salar L.) kelts from a Newfoundland (Canada) river. Fisheries 
540 Reddin DG, Friedland KD, Downton P, Dempson JB, Mullins CC (2004) Thermal habitat experienced by Atlantic salmon (Salmo salar L.) kelts in coastal Newfoundland waters. Fisheries Oceanography 13:24-35

\section{3}

Renkawitz MD, Sheehan TF, Dixon HJ, Nygaard R (2015) Changing trophic structure and energy dynamics in the Northwest Atlantic: implications for Atlantic salmon feeding at West

Renkawitz MD, Sheehan TF, Goulette GS (2012) Swimming depth, behavior, and survival of Atlantic salmon postsmolts in Penobscot Bay, Maine. Trans Am Fish Soc 141:1219-1229

Rikardsen AH, Amundsen PA (2005) Pelagic marine feeding of Arctic charr and sea trout. J Fish Biol 66:1163-1166

Rikardsen AH, Dempson JB (2011) Dietary life-support: the food and feeding of Atlantic salmon at sea. Wiley-Blackwell

Rikardsen AH, Hansen LP, Jensen AJ, Vollen T, Finstad B (2008) Do Norwegian Atlantic salmon feed in the northern Barents Sea? Tag recoveries from 70 to 78 degrees N. J Fish Biol 72:1792-1798

Rikardsen AH, Haugland M, Bjorn PA, Finstad B, Knudsen R, Dempson JB, Holst JC, Hvidsten NA, Holm M (2004) Geographical differences in marine feeding of Atlantic salmon post-smolts in Norwegian fjords. J Fish Biol 64:1655-1679

Rikardsen AH, Thorstad EB (2006) External attachment of data storage tags increases probability of being recaptured in nets compared to internal tagging. J Fish Biol 68:963-968

559 Saunders R (1986) The thermal biology of Atlantic salmon: influence of temperature on salmon 560 culture with particular reference to constraints imposed by low temperature (Salmo salar). Report - Institute of Freshwater Research, Book 63, Drottningholm, Sweden 
562 Strøm J, Thorstad E, Chafe G, Sørbye S, Righton D, Carr J (2017) Ocean migration of pop-up satellite archival tagged Atlantic salmon from the Miramichi River in Canada. ICES J Mar Sci

564 Tanaka H, Takagi Y, Naito Y (2000) Behavioural thermoregulation of chum salmon during homing migration in coastal waters. J Exp Biol 203:1825-1833

566 Walli A, Teo SLH, Boustany A, Farwell CJ, Williams T, Dewar H, Prince E, Block BA (2009) Seasonal movements, aggregations and diving behavior of Atlantic bluefin tuna (Thunnus thynnus) revealed with archival tags. Plos One 4:18

569 Wilson SG, Block BA (2010) Habitat use in Atlantic bluefin tuna Thunnus thynnus inferred from diving behavior. Endangered Species Research 10:355-367 
574 Table 1. The Atlantic salmon from the Orkla, Alta and Neiden Rivers tagged with pop-up

575 satellite archival tags (PSATs) and data storage tags (DSTs). $\mathrm{n}=$ sample size. High and low

576 temporal resolution DSTs are shown by $\mathrm{H}$ and L suffixes respectively. For Atlantic salmon

577 body length and body mass, ranges are shown in parentheses.

578

\begin{tabular}{|c|c|c|c|c|c|c|}
\hline \multirow{2}{*}{$\begin{array}{l}\text { Population } \\
\text { Tag type }\end{array}$} & \multicolumn{2}{|l|}{ Orkla } & \multicolumn{3}{|l|}{ Alta } & \multirow{2}{*}{$\begin{array}{l}\text { Neiden } \\
\text { PSATL }_{L}\end{array}$} \\
\hline & PSATL $_{L}$ & $\mathrm{DST}_{\mathrm{L}}$ & PSATL $_{L}$ & $\mathrm{DST}_{\mathrm{L}}$ & $\mathrm{DST}_{\mathrm{H}}$ & \\
\hline \multicolumn{7}{|l|}{ Release } \\
\hline Years & 2010 & 2010 & $2008-2010$ & $2008-2012$ & 2013-2015 & $2009-2010$ \\
\hline No & 10 & 57 & 47 & 348 & 229 & 16 \\
\hline $\begin{array}{l}\text { Mean body } \\
\text { length (cm) }\end{array}$ & 98 (88-114) & 89 (71-107) & 99 (92-112) & 92 (57-114) & 87 (56-112) & 91 (73-107) \\
\hline $\begin{array}{l}\text { Mean body } \\
\text { mass (kg) }\end{array}$ & 6.7 (4.7-9.8) & $4.8(2-6-9.0)$ & 7.2 (5.4-9.9) & $6.0(1.4-13.0)$ & $5.2(1.2-1.1)$ & $5.4(2.8-9.8)$ \\
\hline \multicolumn{7}{|l|}{ Recovered } \\
\hline No & 10 & 3 & 42 & 22 & 13 & 14 \\
\hline $\begin{array}{l}\text { Mean data } \\
\text { length (d) }\end{array}$ & 147 & 415 & 135 & 407 & 411 & 104 \\
\hline $\begin{array}{l}\text { Mean body } \\
\text { length (cm) }\end{array}$ & 98 (88-114) & 90 (87-94) & $99(92-112)$ & $92(80-104)$ & 92 (79-99) & 92 (73-107) \\
\hline $\begin{array}{l}\text { Mean body } \\
\text { mass (kg) }\end{array}$ & 6.7 (4.7-9.8) & 4.9 (4.5-5.5) & 7.3 (5.4-9.9) & $6.0(4.0-9.0)$ & $5.4(3.2-6.7)$ & 5.7 (2.9-9.8) \\
\hline $\begin{array}{l}\text { Median } \\
\text { recording } \\
\text { interval (min) }\end{array}$ & $\begin{array}{l}15(\mathrm{n}=3) \\
30(\mathrm{n}=7)\end{array}$ & $30(\mathrm{n}=3)$ & $\begin{array}{l}15(\mathrm{n}=18) \\
30(\mathrm{n}=13) \\
45(\mathrm{n}=1) \\
60(\mathrm{n}=10)\end{array}$ & $\begin{array}{l}2(\mathrm{n}=10) \\
30(\mathrm{n}=20)\end{array}$ & $\begin{array}{l}1(n=7) \\
5(n=6)\end{array}$ & $\begin{array}{l}15(n=7) \\
30(n=4) \\
60(n=3)\end{array}$ \\
\hline
\end{tabular}


582 Figure 1. Study area showing positions at pop-up (circles) of PSATs that had been attached to 583 Atlantic salmon from the Orkla (green), Alta (red) and Neiden (yellow) Rivers, with places of 584 release (triangles).

Figure 2. Depth use of all tagged Atlantic salmon from the Orkla, Alta and Neiden Rivers according to month from release: percentage depth frequency distribution (upper panels), median depth (middle panels), and maximum depth (lower panels). Data from the Neiden taggroup were not available after January the year after release. Percentage depth frequency distributions are determined for each salmon individual, and a mean of individual percentage frequency distributions is shown. Median and maximum depths were determined on a daily basis, and the means of these calculated per month are shown. Numbers of individuals used in the estimate are shown above each bar.

Figure 3. Percentage depth frequency distribution of tagged Atlantic salmon from the Orkla, Alta and Neiden Rivers according to hour of day for May - July (upper panels), August October (middle panels) and November - January (lower panels). Hour of day is calibrated to the position of release. Percentage depth frequency distributions are determined for each salmon individual, and a mean of individual percentage frequency distributions is shown. The actual time of day experienced by the salmon will be offset by this by +1 hour for every $15^{\circ}$ the individual moves eastward and -1 hour for every $15^{\circ}$ westward.

Figure 4. Absolute vertical velocity of 13 Atlantic salmon from the River Alta carrying high temporal resolution DSTs according to hour of day for May - July, August - October, and 
605 November - January. Hour of day is that recorded using a clock calibrated to the position of 606 release.

607

608 Figure 5. Deep dive characteristics (>200 m) for selected Atlantic salmon from the River Alta 609 carrying DSTs: (a) 'U' shaped pattern; (b) skewed 'U' shape pattern; (c) movement to depth 610 with multiple depth fluctuations before surfacing; and (d) movement to depth followed by 611 sustained presence as a shallower depth before surfacing. Positive diving velocities indicate 612 the descending phase, and negative diving velocities indicate the ascending phase.

613

614 Figure 6. Characteristics of the deep dives (>200 m) by 13 Atlantic salmon from the River 615 Alta carrying high temporal resolution DSTs: (a) diving velocity; (b) maximum depth; (c) 616 length of dive; and (d) difference between surface and trough (maximum depth) temperatures. 617

618 Figure 7. Long-term trend of diving behaviour of 13 Atlantic salmon from the River Alta 619 carrying high temporal resolution DSTs: (a) depth and temperature versus time; (b) median 620 depth of dives where depth $>25 \mathrm{~m}$; and (c) total number of dives (depth $>25 \mathrm{~m}$ ) and number 621 of deep dives (depth $>200 \mathrm{~m}$ ). The depth of the mixed layer (solid line), calculated for a 622 convex polygon encompassing all pop-up locations for these individuals, has been 623 superimposed on (a) and (b) (obtained from the Operational Mercator Global Ocean Analysis 624 and Forecast System through the Copernicus Marine Environment Service). In (b) and (c) 625 numbers above each box show the number of individuals.

626

627 Supplementary figure 1. Depth and temperature versus time for 7 recovered Atlantic salmon 628 from the River Alta tagged with high temporal resolution DSTs released in 2015. The depth 629 of the mixed layer (solid line), calculated for a convex polygon encompassing all pop-up 
630 locations for the Alta salmon tagged with high resolution DSTs, has been superimposed

631 (obtained from the Operational Mercator Global Ocean Analysis and Forecast System through 632 the Copernicus Marine Environment Service).

633 


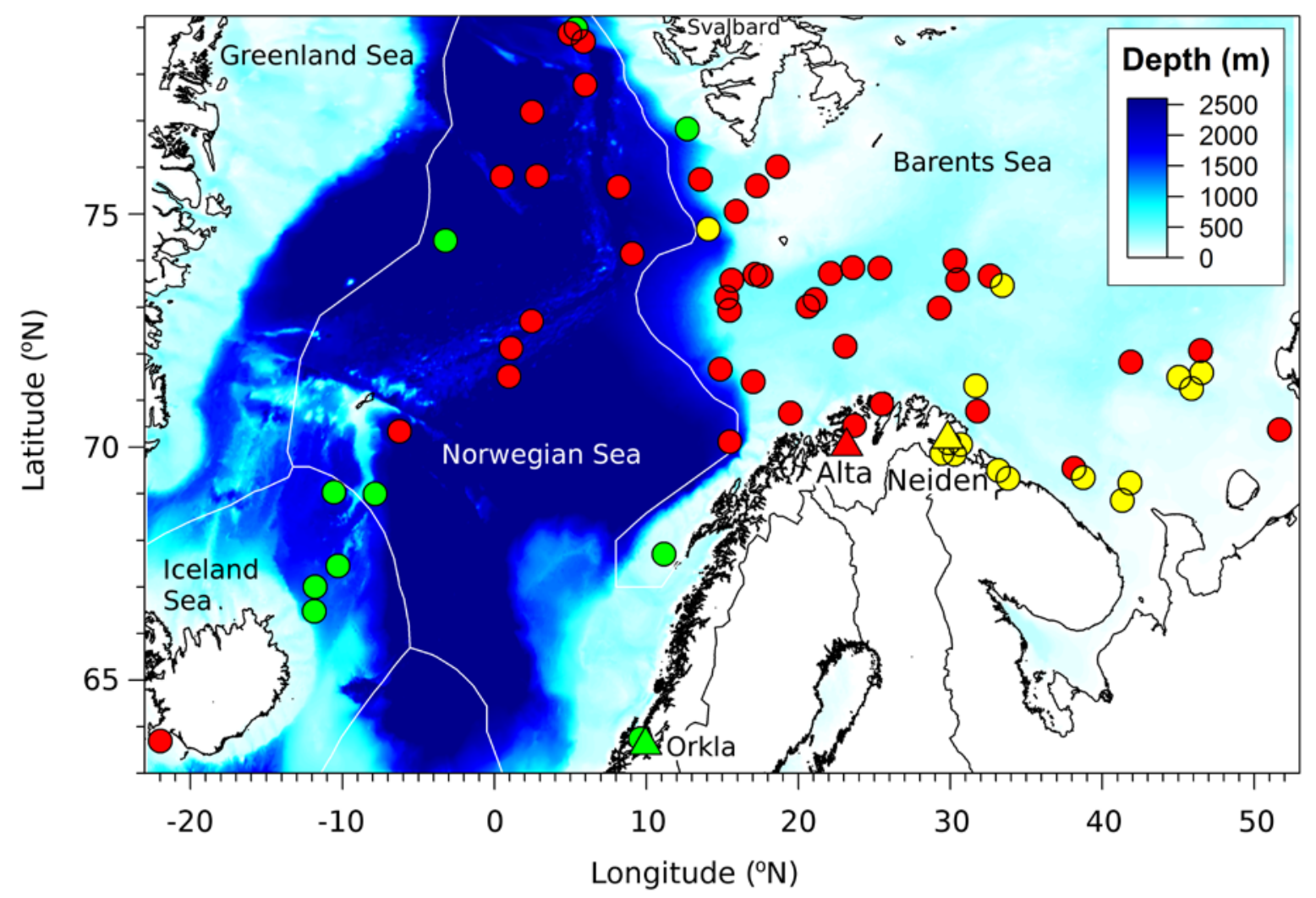

635

636 Figure 1. Study area showing positions at pop-up (circles) of PSATs that had been attached to

637 Atlantic salmon from the Orkla (green), Alta (red) and Neiden (yellow) Rivers, with places of 638 release (triangles).

639 


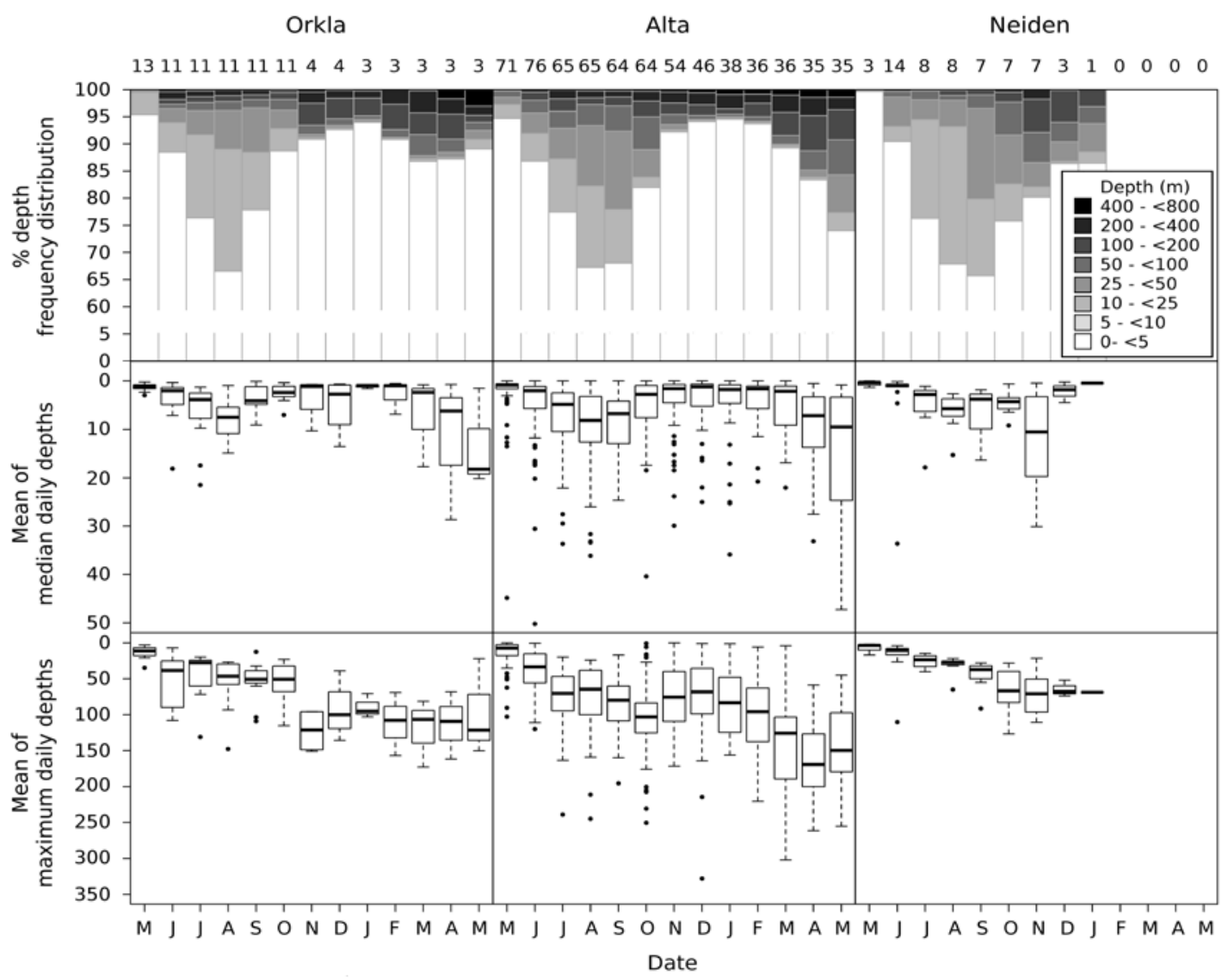

640

641 Figure 2. Depth use of all tagged Atlantic salmon from the Orkla, Alta and Neiden Rivers

642 according to month from release: percentage depth frequency distribution (upper panels),

643 median depth (middle panels), and maximum depth (lower panels). Data from the Neiden tag-

644 group were not available after January the year after release. Percentage depth frequency

645 distributions are determined for each salmon individual, and a mean of individual percentage

646 frequency distributions is shown. Median and maximum depths were determined on a daily

647 basis, and the means of these calculated per month are shown. Numbers of individuals used in

648 the estimate are shown above each bar. 


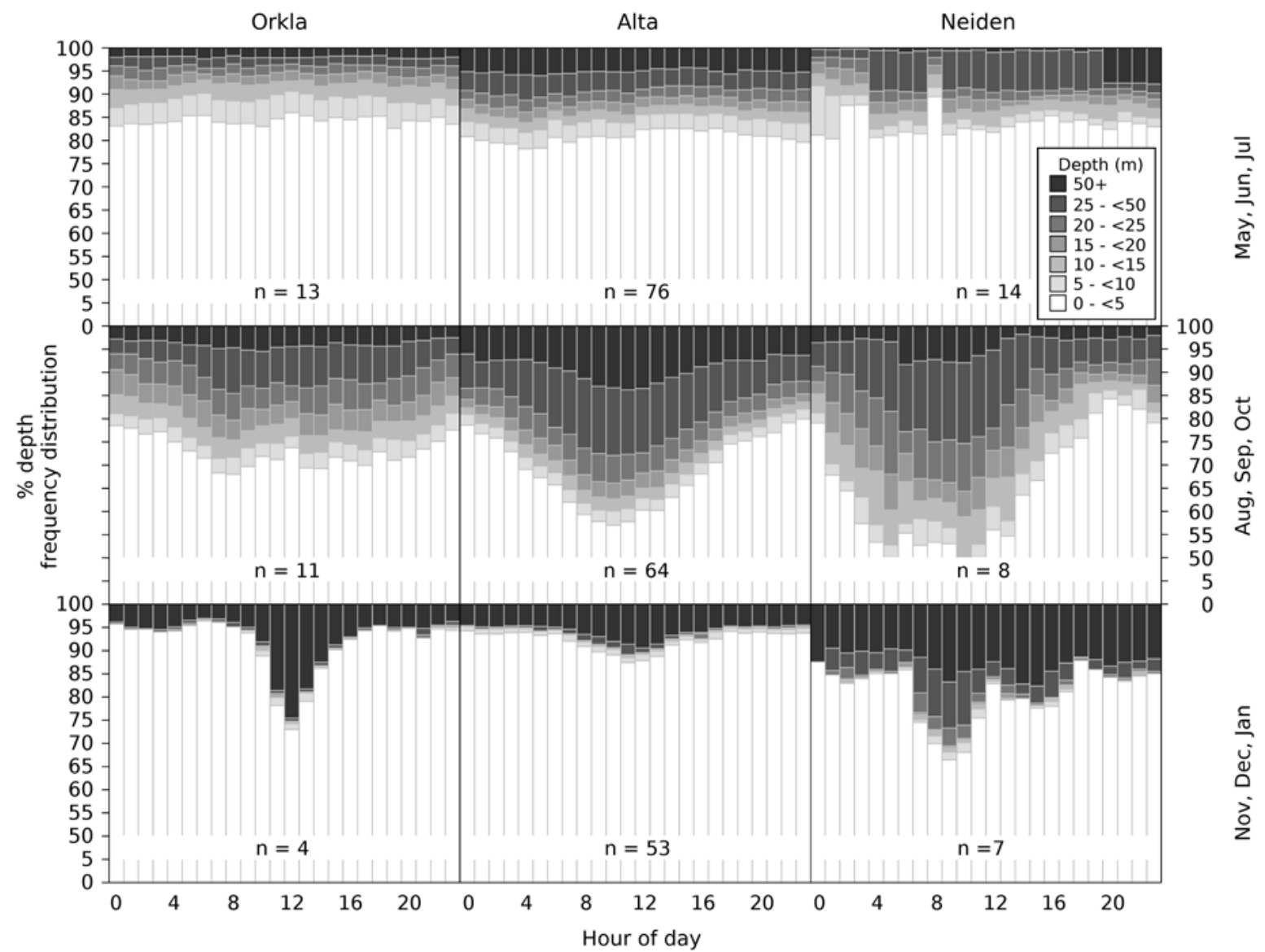

649

Figure 3. Percentage depth frequency distribution of tagged Atlantic salmon from the Orkla,

651 Alta and Neiden Rivers according to hour of day for May - July (upper panels), August -

652 October (middle panels) and November - January (lower panels). Hour of day is calibrated to

653 the position of release. Percentage depth frequency distributions are determined for each

654 salmon individual, and a mean of individual percentage frequency distributions is shown. The

655 actual time of day experienced by the salmon will be offset by this by +1 hour for every $15^{\circ}$

656 the individual moves eastward and -1 hour for every $15^{\circ}$ westward. 


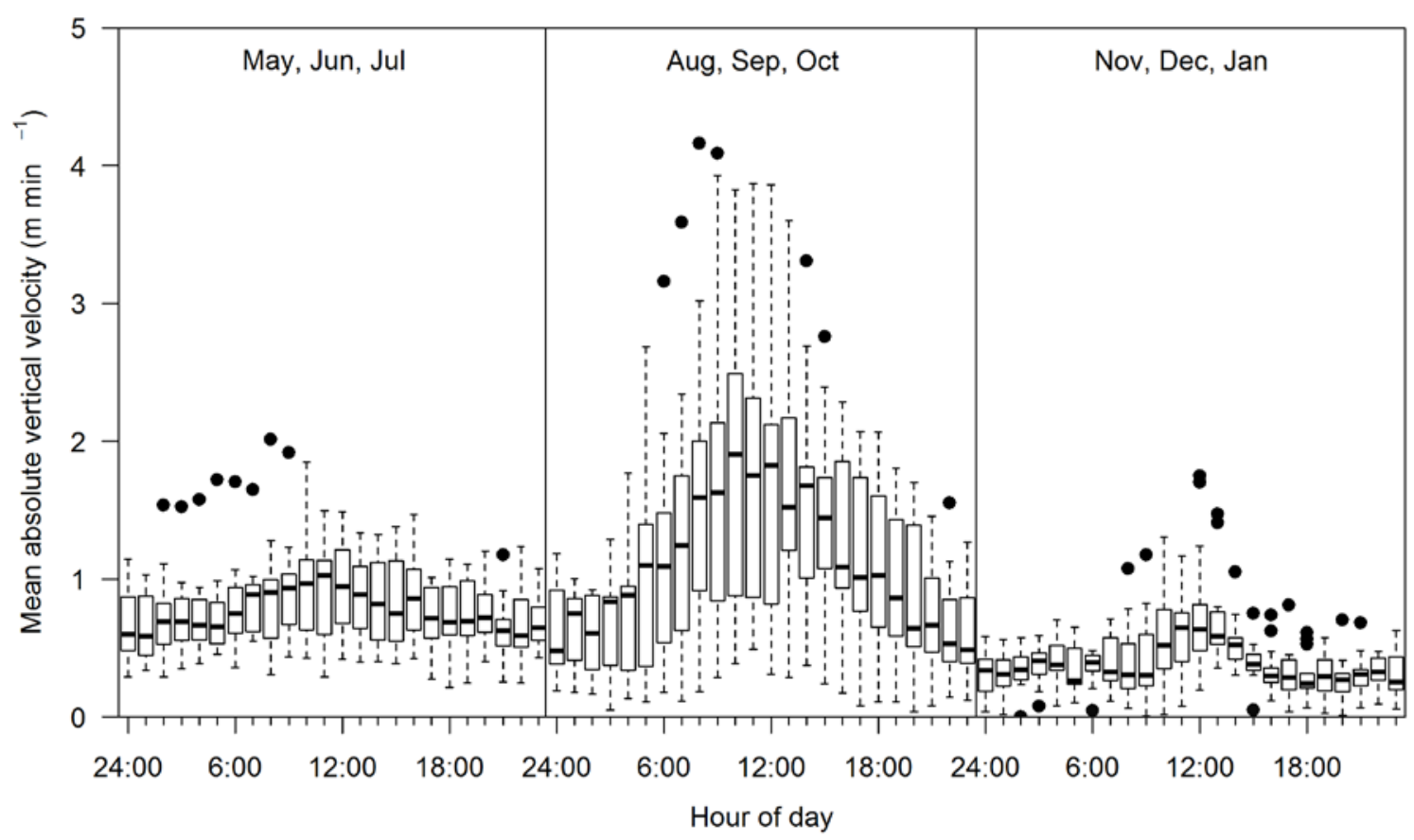

657

658 Figure 4. Absolute vertical velocity of 13 Atlantic salmon from the River Alta carrying high

659 temporal resolution DSTs 
(a)

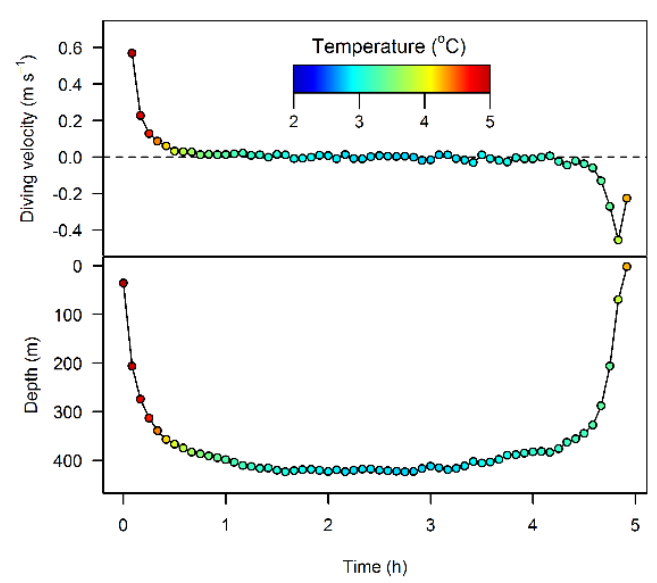

(c)

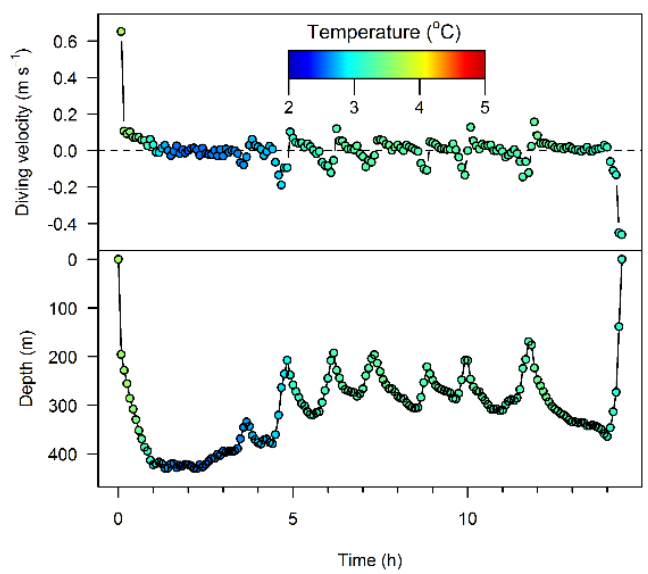

(b)

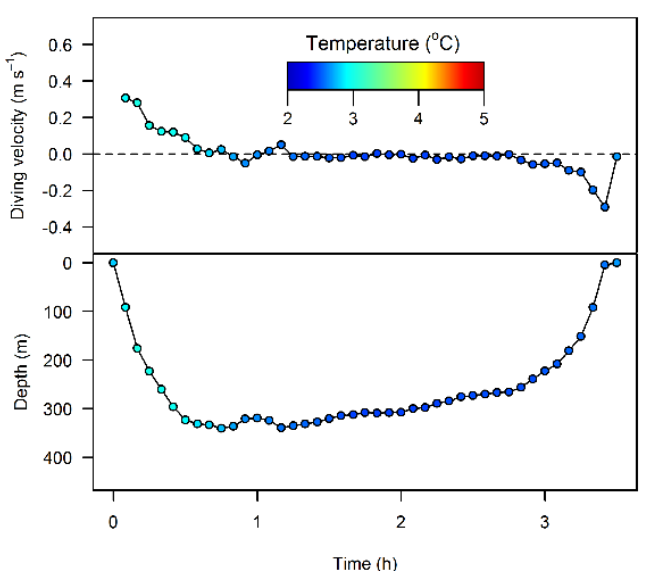

(d)

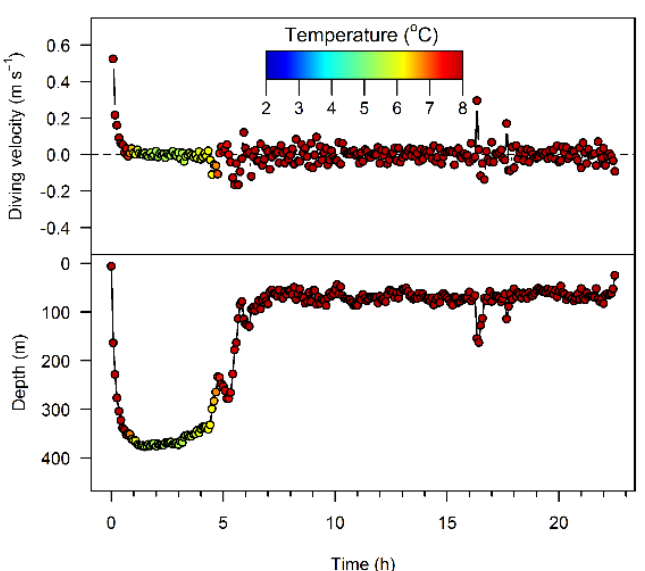

660

661 Figure 5. Deep dive characteristics (>200 m) for selected Atlantic salmon from the River Alta

662 carrying DSTs: (a) 'U’ shaped pattern; (b) skewed 'U' shape pattern; (c) movement to depth

663 with multiple depth fluctuations before surfacing; and (d) movement to depth followed by

664 sustained presence as a shallower depth before surfacing. Positive diving velocities indicate

665 the descending phase, and negative diving velocities indicate the ascending phase. 
(a)

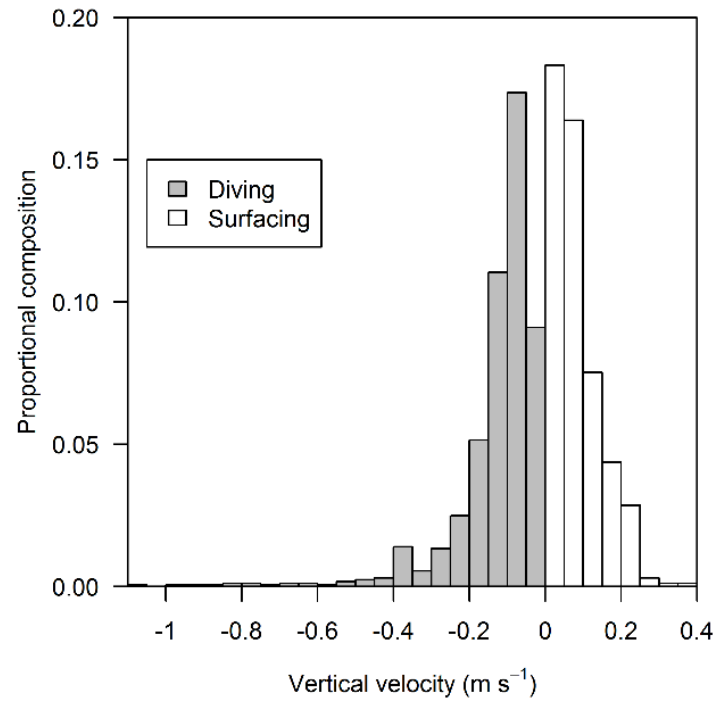

(c)

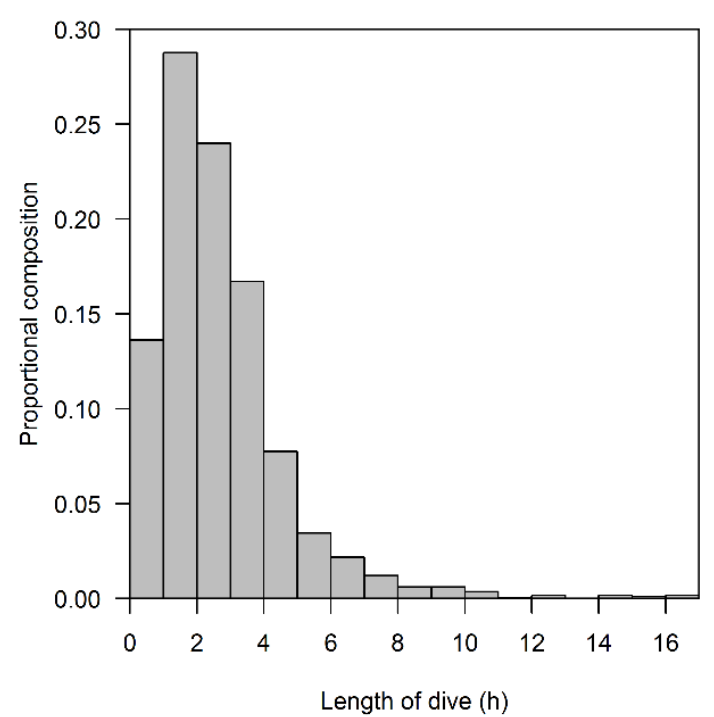

(b)

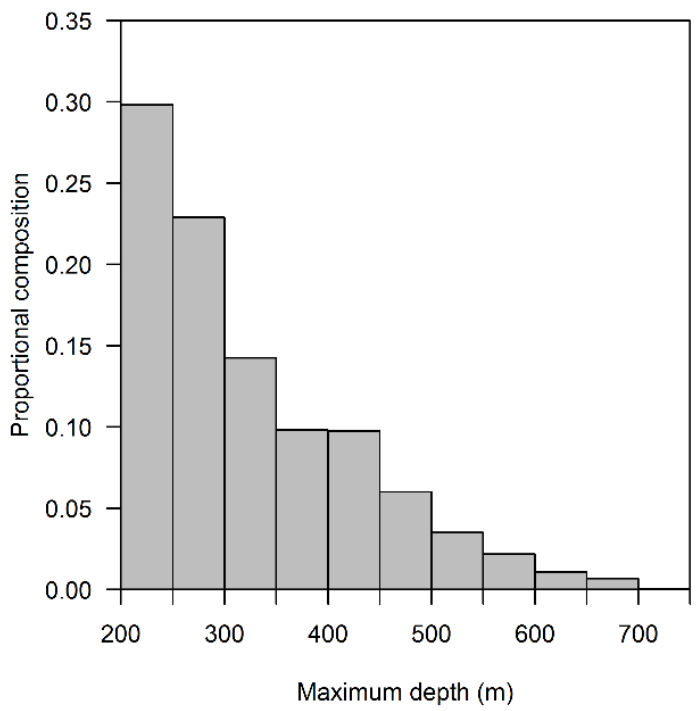

(d)

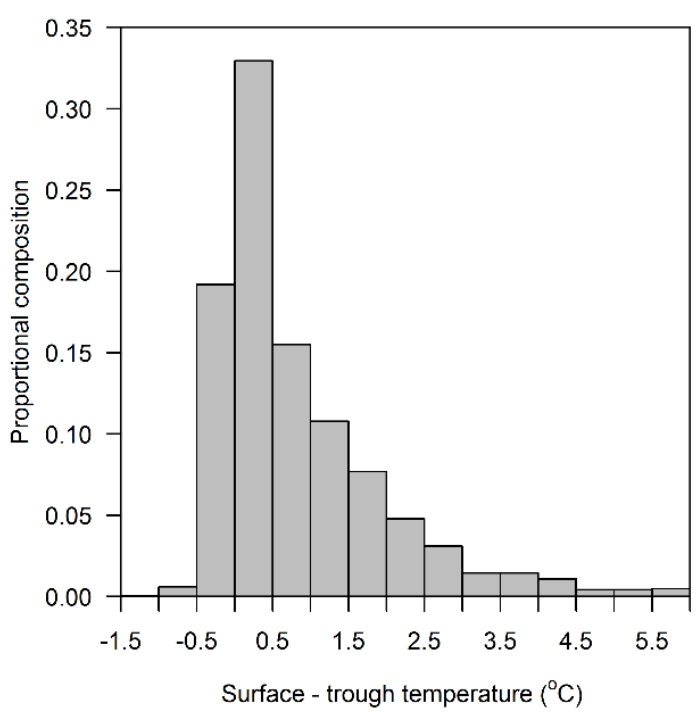

668 Figure 6. Characteristics of the deep dives ( $>200 \mathrm{~m}$ ) by 13 Atlantic salmon from the River

669 Alta carrying high temporal resolution DSTs: (a) diving velocity; (b) maximum depth; (c)

670 length of dive; and (d) difference between surface and trough (maximum depth) temperatures. 
(a)

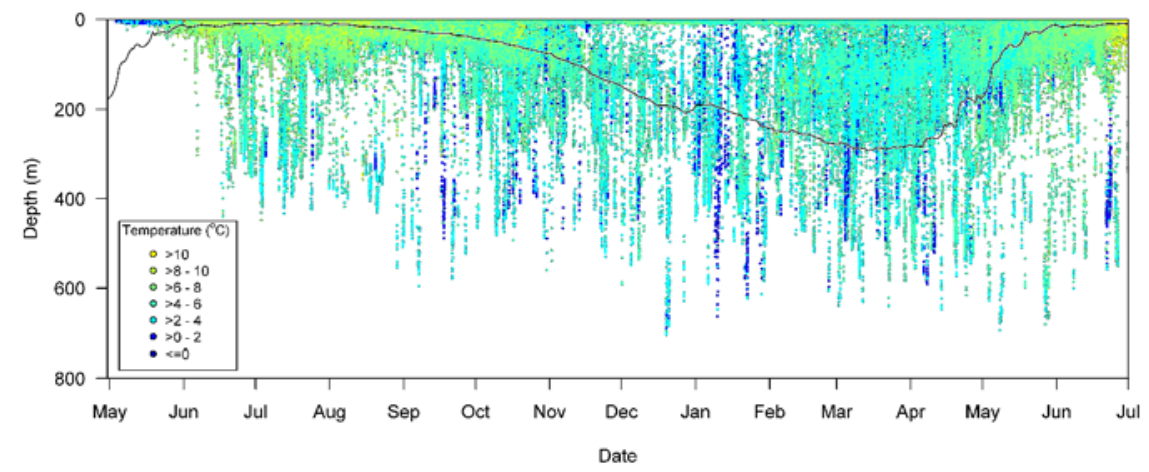

(b)

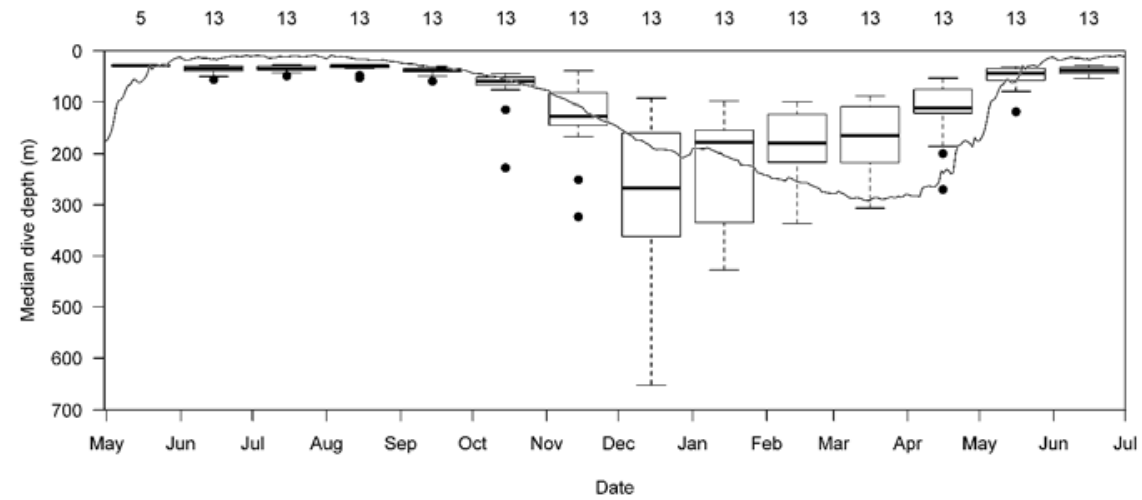

(c)

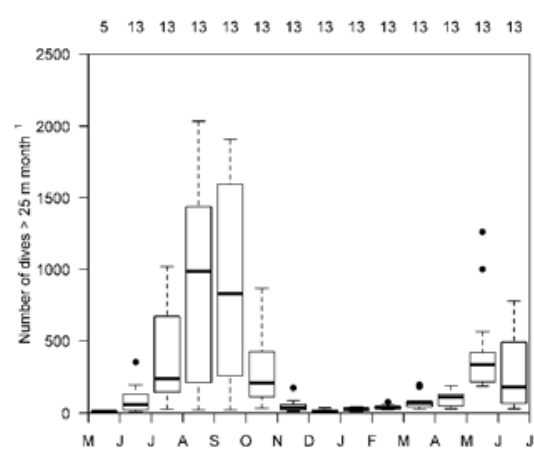

Date

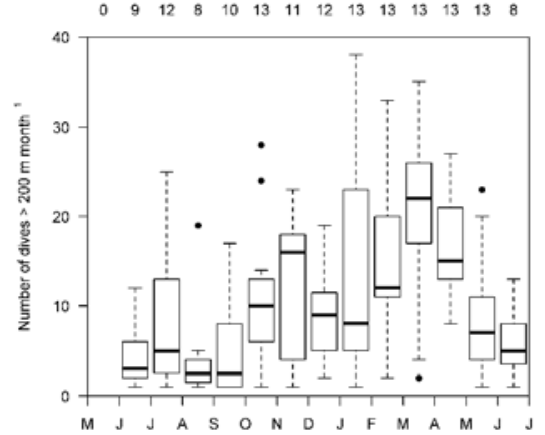

Date

673 Figure 7. Long-term trend of diving behaviour of 13 Atlantic salmon from the River Alta

674 carrying high temporal resolution DSTs: (a) depth and temperature versus time; (b) median

675 depth of dives where depth $>25 \mathrm{~m}$; and (c) total number of dives (depth $>25 \mathrm{~m}$ ) and number

676 of deep dives (depth $>200 \mathrm{~m}$ ). The depth of the mixed layer (solid line), calculated for a

677 convex polygon encompassing all pop-up locations for these individuals, has been

678 superimposed on (a) and (b) (obtained from the Operational Mercator Global Ocean Analysis

679 and Forecast System through the Copernicus Marine Environment Service). In (b) and (c)

680 numbers above each box show the number of individuals. 
682
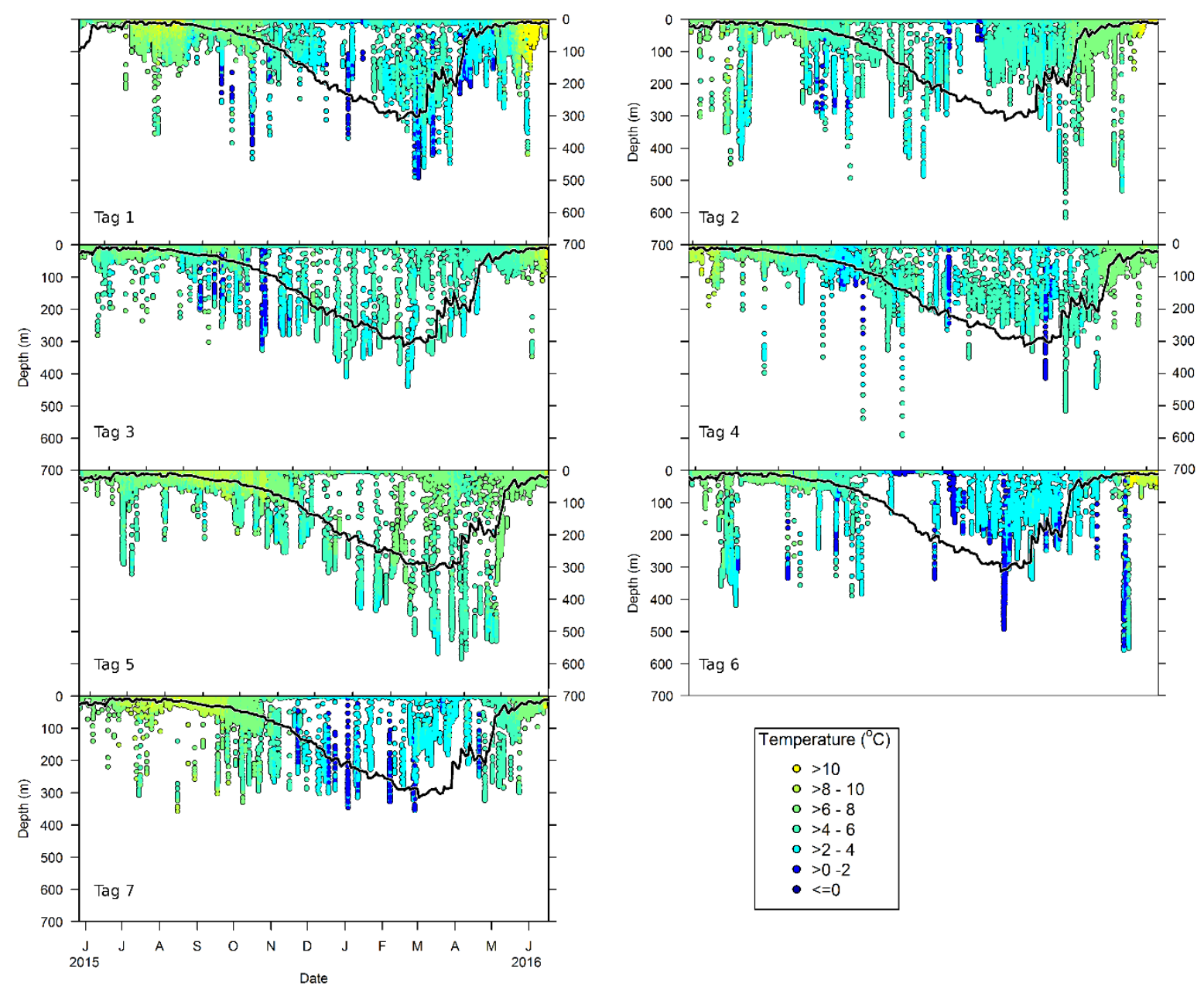

683

684 Supplementary figure 1. Depth and temperature versus time for 7 recovered Atlantic salmon

685 from the River Alta tagged with high temporal resolution DSTs released in 2015. 